\title{
$\mathrm{BMJ}$
}

\section{Induction versus expectant monitoring for intrauterine growth restriction at term: randomised equivalence trial (DIGITAT)}

${ }^{1}$ Leiden University Medical Centre, Leiden, Netherlands

${ }^{2}$ Academic Medical Centre, Amsterdam, Netherlands

${ }^{3}$ Onze Lieve Vrouwe Gasthuis, Amsterdam, Netherlands

${ }^{4}$ University Medical Centre, Utrecht, Netherlands

${ }^{5}$ Meander Medical Centre, Amersfoort, Netherlands

${ }^{6}$ University Medical Centre St Radboud, Nijmegen, Netherlands

${ }^{7}$ Hospital Rijnstate, Arnhem, Netherlands

${ }^{8}$ Erasmus MC, University Medical Centre, Rotterdam, Netherlands

${ }^{9}$ Reinier de Graaf Hospital, Delft, Netherlands

${ }^{10}$ Catharina Hospital, Eindhoven, Netherlands

${ }^{11}$ Elkerliek Hospital, Helmond, Netherlands

${ }^{12}$ Groene Hart Hospital, Gouda, Netherlands

${ }^{13}$ University Hospital Maastricht, Netherlands

${ }^{14}$ VieCuri Medical Centre, Venlo, Netherlands

${ }^{15}$ Atrium Medical Centre, Heerlen, Netherlands

${ }^{16}$ Nottingham City Hospital, Nottingham, United Kingdom

Correspondence to: K E Boers, Bronovo Hospital, The Hague Department of Obstetrics and Gynaecology Bronovolaan 5, 2597 AX, The Hague, Netherlands k.e.boers@lumc.nl

Cite this as: $B M J$ 2010;341:c7087 doi:10.1136/bmj.c7087

\begin{abstract}
K E Boers, obstetrician, ${ }^{1}$ S M C Vijgen, health economist, ${ }^{2}$ D Bijlenga, psychologist, senior researcher , ${ }^{2}$ I A M van der Post, obstetrician, , ${ }^{2}$ D J Bekedam, obstetrician, ${ }^{3}$ A Kwee, obstetrician, ${ }^{4}$ P C M van der Salm, obstetrician, ${ }^{5}$ M G van Pampus, obstetrician, ${ }^{3}$ M E A Spaanderman, obstetrician, ${ }^{6} \mathrm{~K}$ de Boer, obstetrician, ${ }^{7}$ J J Duvekot, obstetrician, ${ }^{8}$ H A Bremer, obstetrician, ${ }^{9}$ T H M Hasaart, obstetrician, ${ }^{10}$ F M C Delemarre, obstetrician, ${ }^{11} \mathrm{~K}$ W M Bloemenkamp, obstetrician, ${ }^{1}$ C A van Meir, obstetrician, ${ }^{12}$ C Willekes, obstetrician, ${ }^{13} \mathrm{E}$ J Wijnen, obstetrician, ${ }^{14}$ M Rijken, neonatologist, ${ }^{1}$ S le Cessie, statistician, ${ }^{1}$ F J M E Roumen, obstetrician , ${ }^{15}$ J G Thornton, obstetrician, ${ }^{16}$ J M M van Lith, obstetrician, ${ }^{1}$ B W J Mol, obstetrician, ${ }^{2}$ S A Scherjon, obstetrician ${ }^{1}$ on behalf of the DIGITAT study Group
\end{abstract}

\section{ABSTRACT}

Objective To compare the effect of induction of labour with a policy of expectant monitoring for intrauterine growth restriction near term.

Design Multicentre randomised equivalence trial (the Disproportionate Intrauterine Growth Intervention Trial At Term (DIGITAT)).

Setting Eight academic and 44 non-academic hospitals in the Netherlands between November 2004 and November 2008.

Participants Pregnant women who had a singleton pregnancy beyond $36+0$ weeks' gestation with suspected intrauterine growth restriction.

Interventions Induction of labour or expectant monitoring.

Main outcome measures The primary outcome was a composite measure of adverse neonatal outcome, defined as death before hospital discharge, five minute Apgar score of less than 7, umbilical artery $\mathrm{pH}$ of less than 7.05 , or admission to the intensive care unit. Operative delivery (vaginal instrumental delivery or caesarean section) was a secondary outcome. Analysis was by intention to treat, with confidence intervals calculated for the differences in percentages or means.

Results 321 pregnant women were randomly allocated to induction and 329 to expectant monitoring. Induction group infants were delivered 10 days earlier (mean difference -9.9 days, $95 \% \mathrm{Cl}-11.3$ to -8.6$)$ and weighed $130 \mathrm{~g}$ less (mean difference $-130 \mathrm{~g}, 95 \% \mathrm{Cl}-188 \mathrm{~g}$ to $-71 \mathrm{~g}$ ) than babies in the expectant monitoring group. A total of 17 (5.3\%) infants in the induction group experienced the composite adverse neonatal outcome, compared with 20 (61\%) in the expectant monitoring group (difference $-0.8 \%, 95 \% \mathrm{Cl}-4.3 \%$ to $3.2 \%$ ). Caesarean sections were performed on 45 (14.0\%) mothers in the induction group and $45(13.7 \%)$ in the expectant monitoring group (difference $0.3 \%, 95 \% \mathrm{Cl}$ $-5.0 \%$ to $5.6 \%$ ).
Conclusions In women with suspected intrauterine growth restriction at term, we found no important differences in adverse outcomes between induction of labour and expectant monitoring. Patients who are keen on non-intervention can safely choose expectant management with intensive maternal and fetal monitoring; however, it is rational to choose induction to prevent possible neonatal morbidity and stillbirth. Trial registration International Standard Randomised Controlled Trial number ISRCTN10363217.

\section{INTRODUCTION}

Most infants with intrauterine growth restriction are born at term. ${ }^{1}$ Growth restriction so late in gestation is associated with increased perinatal morbidity in the form of fetal distress, hypoglycaemia, seizures, behavioural problems, cerebral palsy, and cardiovascular disease, as well as perinatal mortality. ${ }^{2-11}$ Obstetricians often induce labour in cases of intrauterine growth restriction for fear of neonatal morbidity and later stillbirth. However, observational comparisons of such infants with matched fetuses delivered after spontaneous labour have shown no reduction in short term adverse neonatal outcomes. Induction might increase obstetric interventions ${ }^{12-14}$ and even cause neonatal morbidity if performed before 39 weeks. ${ }^{15-18}$ For these reasons, expectant management with maternal and fetal monitoring is a commonly followed strategy.

The Disproportionate Intrauterine Growth Intervention Trial At Term (DIGITAT) was designed to compare the effect of induction of labour with expectant monitoring on a composite adverse neonatal outcome and on operative delivery rates in infants with suspected growth restriction beyond 36 weeks' gestation. In a pilot trial comparing these two interventions in 33 women, neonatal outcomes and operative 
delivery rates were comparable, but the precision of the estimate of the effect size was limited. ${ }^{19}$

\section{METHODS}

The trial was run by the Dutch Obstetric Consortium, a collaboration of perinatal centres in the Netherlands, and approved by the University of Leiden institutional review board. The study was staffed by obstetricians, research nurses, and midwives associated with the Dutch Obstetric Consortium. They counselled and recruited participants, monitored compliance with allocated treatment protocols, and collected outcome data.

Recruitment ran from November 2004 to November 2008. The study began in four hospitals, but by the end of the study period recruitment had been rolled out to 52 maternity hospitals in Holland. Making the crude assumptions that the average centre recruited for half the trial duration of three years (that is, 18 months), that each centre delivered 1500 women a year (adjusting for women seen only in labour or who were ineligible because of multiple pregnancy or breech pregnancy), and assuming that half of all growth restricted fetuses are detectable, we anticipated that about 1326 potentially eligible women would be identified over the recruitment period.

\section{Participants}

Pregnant women between $36+0$ and $41+0$ weeks' gestation who had a singleton fetus in cephalic presentation, suspected intrauterine growth restriction, and who were under specialised obstetric care were recruited. Suspected intrauterine growth restriction was defined as fetal abdominal circumference below the 10th percentile, estimated fetal weight below the 10th percentile, flattening of the growth curve in the third trimester (as judged by a clinician), or the presence of all three factors. ${ }^{20}$ Both fetuses with abnormal Doppler flow velocity measurements and those with normal Doppler flow velocity measurements were included.

The DIGITAT recruitment period overlapped with recruitment for the Hypertension Intervention Trial At Term (HYPITAT), ${ }^{21}$ which compared similar interventions in women with gestational hypertension and mild pre-eclampsia at term. Patients with both suspected intrauterine growth restriction and hypertension were preferentially recruited to DIGITAT, and women could not participate in both studies. Gestational hypertension and pre-eclampsia were defined according to criteria from the International Society for the Study of Hypertension in Pregnancy. ${ }^{22}$ Oligohydramnios was defined as an amniotic fluid index of $5 \mathrm{~cm}$ or less.

Exclusion criteria were previous caesarean section, diabetes mellitus or gestational diabetes requiring insulin therapy, renal failure, HIV seropositivity, prelabour rupture of membranes, severe pre-eclampsia, HELLP syndrome (haemolysis, elevated liver enzymes, and low platelet count), or a fetus with aneuploidy or congenital abnormalities suspected on ultrasound. Fetuses with decreased or absent movements, and those with abnormal heart rate tracings, were also excluded.
Cervical length was measured using transvaginal sonography and vaginal digital examination was performed to assess the Bishop score before randomisation. ${ }^{23}$

\section{Randomisation}

Participant data were entered into a secure web based database. Women were randomly allocated to either induction or expectant monitoring in a 1:1 ratio using varied sized block randomisation with stratification for centre and parity (nulliparous or parous women). Women who declined consent for randomisation but authorised use of their medical data were treated at the discretion of the local obstetrician and included in the database. These data were used to study external validity of the trial. Women who refused both randomisation and collection of identifiable data were registered anonymously. It was not possible to blind participants, obstetricians, or outcome assessors. Written informed consent was obtained from all participants before randomisation.

Participants allocated to the induction of labour group were induced within 48 hours of randomisation. If the Bishop score at randomisation was greater than 6 , labour was induced with amniotomy and, if necessary, augmented with oxytocin. Otherwise cervical ripening was performed with intracervical or intravaginal prostaglandin (E1 or E2 analogue, repeated once after six hours) or a Foley balloon catheter filled with $30 \mathrm{~mL}$ sodium chloride. ${ }^{24}$

Participants allocated to the expectant monitoring group were monitored until the onset of spontaneous labour with daily fetal movement counts and twice weekly heart rate tracings, ultrasound examination, maternal blood pressure measurement, assessment of proteinuria, laboratory tests of liver and kidney function, and full blood count. Women were monitored as either an outpatient or an inpatient, according to local protocol. In the expectant monitoring group, induction of labour or planned caesarean section was performed for obstetrical indications - such as suboptimal fetal heart rate tracings, prolonged rupture of membranes, or postmaturity between $\mathrm{T}+7$ and $\mathrm{T}+$ 14 days - at the obstetrician's discretion.

\section{Outcomes}

The primary outcome was a composite measure of adverse neonatal outcome. This was defined as death before hospital discharge, five minute Apgar score of less than 7, umbilical artery $\mathrm{pH}$ of less than 7.05 , or admission to neonatal intensive care. If the umbilical artery $\mathrm{pH}$ data were missing and all other components of the composite outcome were normal, the neonatal outcome was classified as normal. Secondary outcomes were delivery by caesarean section, instrumental vaginal delivery, length of stay in the neonatal intensive care or neonatal ward, length of stay in the maternal hospital, and maternal morbidity. The latter was defined as postpartum haemorrhage of more than $1000 \mathrm{~mL}$, development of gestational hypertension or pre-eclampsia (according to International Society for the Study of Hypertension in Pregnancy criteria), ${ }^{21}$ 
eclampsia, pulmonary oedema, thromboembolism, or any other serious adverse event.

\section{Study design, sample size, and statistical analysis}

The trial was designed as an equivalence trial in which the null hypothesis was that the difference in the risk of the composite outcome between the two treatment groups was greater than 5.5\% (absolute percentage). Assuming that the rate in the control group was $6 \%$ (on the basis of data from the National Dutch Perinatal Registry $^{25}$ ), this meant that we would exclude the null hypothesis and conclude that the two treatments were equivalent if the boundaries of the confidence interval of the observed risk difference were between $-5.5 \%$ and $5.5 \%$. With a 0.05 risk of type I error $(\alpha)$ and $80 \%$ $(1-\beta)$ power, we calculated that we would require 650 participants (325 per group). The sample size formula for equivalence testing on page 39 of Jones et $\mathrm{al}^{26}$ was used to calculate these numbers, assuming that the induction rate and the control rate were both equal to $6 \%$ under the alternative of equivalence.

Data were analysed according to the intention to treat principle. Continuous variables were summarised as means with standard deviations, or medians with interquartile ranges (IQR). Treatment effects were presented as differences in means or percentages with $95 \%$ confidence intervals $(\mathrm{CI})$. Equivalence of the primary outcome measure was tested by checking if the $95 \%$ CI of the risk difference lay within the equivalence margins. Continuous variables were compared using the Student's $t$ test or the non-parametric Mann-Whitney U test. The $\chi^{2}$ test was used for categorical variables. Instances were more than $5 \%$ of the observations were missing are indicated in the footnotes of the tables.

In a secondary analysis, the primary and secondary outcomes for the two groups were compared after exclusion of women with hypertension related diseases (pre-existing hypertension, gestational hypertension, and pre-eclampsia) at randomisation. Given that randomisation was stratified for centre and parity, we also

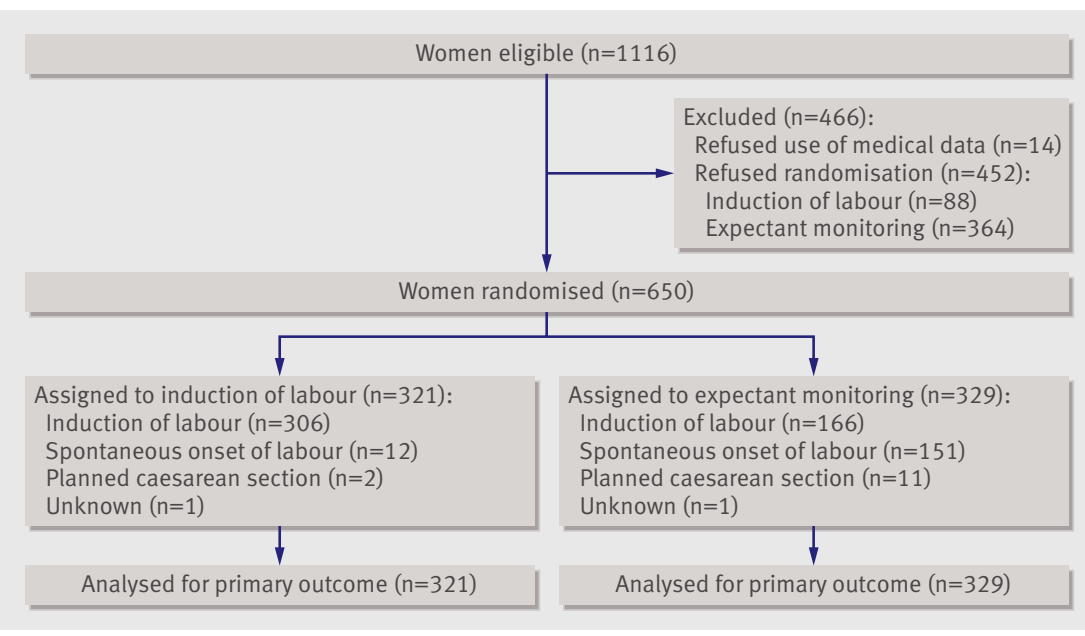

Flow diagram of the trial process performed a stratified analysis for the primary outcome by using logistic regression with parity as fixed covariate and centre as random covariate. Statistical analyses were performed using SPSS software (version 16.0; IBM, Chicago, IL) and Stata software (version 10.1; Stata Corp, College Station, TX).

\section{RESULTS}

A total of 1116 potentially eligible women were identified. Of these women, 14 refused any use of identifiable data and 452 declined randomisation. This left 650 participants, who were randomly assigned to induction $(n=321)$ or expectant monitoring $(n=329$; fig 1$)$. The baseline characteristics of participants in the two randomised arms and in the non-randomised group are shown in table 1. Compared with the induction group, women in the expectant monitoring group were more likely to have a Bishop score of less than or equal to 6 and have gestational hypertension, but otherwise the two randomised arms were comparable. Women who declined randomisation were older, had a higher education level, were less likely to smoke, had a lower body mass index (BMI), and were less likely to have a fetal abdominal circumference below the 10th centile. Most women who were randomised met either the fetal abdominal circumference below 10th centile inclusion criterion or the estimated fetal weight below the 10 th centile criterion. Only 13 women in the induction group and 10 women in the expectant monitoring group were included because of flattening of the growth curve in isolation.

Details of the onset of labour are shown in table 2 , and pregnancy outcomes are shown in table 3 . Trial compliance was good, with induction performed in $306(95.6 \%)$ women in the induction group and in only $166(50.6 \%)$ in the expectant monitoring group, resulting in a median time from randomisation to onset of labour of 0.9 days (IQR 0.7-1.7) in the induction group and 10.4 days (IQR 5.6-16.0) in the expectant monitoring group.

Labour was induced in $166(50.6 \%)$ women in the expectant monitoring group: 92 for suspected fetal distress; 21 for hypertensive disorders; 24 on maternal request; nine for prelabour rupture of membranes; five for post-term pregnancy; and 15 for unspecified maternal reasons. Planned caesarean section was performed in two $(0.6 \%)$ women in the induction arm: one because of fetal distress, the second because of primary genital herpes infection. A total of 11 (3.3\%) women in the expectant monitoring arm had a planned caesarean section: in 10 cases for fetal distress and one for unpredicted breech position. In the expectant monitoring arm, the median time from randomisation to delivery among women who delivered by planned caesarean section was 4.5 days. The numbers of operative and instrumental deliveries were comparable between the groups $(27(8.4 \%)$ in the induction group and $27(8.2 \%)$ in the expectant monitoring group).

One $(0.3 \%)$ woman allocated to induction of labour died at home 10 days after delivery. She had delivered a healthy child vaginally at $38+4$ weeks of gestation 


\begin{tabular}{|c|c|c|c|}
\hline & $\begin{array}{l}\text { Induction of labour } \\
\text { group }(n=321)\end{array}$ & $\begin{array}{c}\text { Expectant } \\
\text { monitoring group } \\
(\mathrm{n}=329)\end{array}$ & $\begin{array}{l}\text { Non-randomised } \\
\text { group }(n=452)\end{array}$ \\
\hline Nulliparous & $182(56.7)$ & $201(61.1)$ & $275(61.0)$ \\
\hline Maternal age & $27(23-31)$ & $27(23-31)$ & $31(27-34)$ \\
\hline BMI at study entry $\dagger$ & $22(20-25)$ & $22(20-26)$ & $21(20-24)$ \\
\hline Gestational age (days) & $263(258-269)$ & $263(258-270)$ & $262(258-269)$ \\
\hline White racef & $254(83.6)$ & $253(81.1)$ & $344(83.3)$ \\
\hline \multicolumn{4}{|l|}{ Education } \\
\hline Lower professional school & $168(52.3)$ & $170(51.7)$ & $149(33.0)$ \\
\hline Medium professional school & $26(8.1)$ & $37(11.2)$ & $93(20.6)$ \\
\hline Unknown & $127(39.6)$ & $122(37.1)$ & $209(46.3)$ \\
\hline Maternal smoking§ & $138(46.9)$ & $127(40.8)$ & $114(26.9)$ \\
\hline \multicolumn{4}{|l|}{ Blood pressure at booking } \\
\hline Systolic & $115(105-120)$ & 114 (106-120) & $115(110-120)$ \\
\hline Diastolic & $70(60-75)$ & $66(60-75)$ & $70(60-75)$ \\
\hline Gestational hypertension & $9(2.8)$ & $19(5.8)$ & $25(5.5)$ \\
\hline Pre-eclampsia & $18(5.6)$ & $27(8.2)$ & $27(6.0)$ \\
\hline \multicolumn{4}{|l|}{ Inclusion criteria } \\
\hline $\begin{array}{l}\text { Fetal abdominal circumference «10th } \\
\text { percentile }\end{array}$ & $262(81.6)$ & $270(82.1)$ & $354(78.5)$ \\
\hline $\begin{array}{l}\text { Estimated fetal weight }<10 \text { th } \\
\text { percentile }\end{array}$ & $296(92.2)$ & 308 (93.6) & $418(92.5)$ \\
\hline $\begin{array}{l}\text { Deceleration of fetal abdominal } \\
\text { circumference curve }\end{array}$ & $83(25.9)$ & $84(25.5)$ & $95(21.0)$ \\
\hline Fetal abdominal circumference (mm) & $287(278-297)$ & $289(279-297)$ & $289(278-299)$ \\
\hline Oligohydramniosף & $87(31.0)$ & $101(34.5)$ & $145(34.4)$ \\
\hline \multicolumn{4}{|l|}{ Umbilical artery Dopplert† } \\
\hline $\begin{array}{l}\text { Pulsatility index in the umbilical } \\
\text { artery }\end{array}$ & $0.98(0.85-1.13)$ & $0.93(0.82-1.10)$ & $0.96(0.84-1.11)$ \\
\hline Absent & $7(2.7)$ & $7(2.5)$ & $4(1.0)$ \\
\hline Reversed & 0 & 0 & $1(0.2)$ \\
\hline 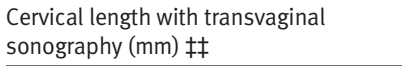 & $30(22-37)$ & $30(24-38)$ & $33(22-41)$ \\
\hline Bishop score $\leq 6 \S \S$ & $280(94.0)$ & $293(97.3)$ & 64 (98.5) \\
\hline \multicolumn{4}{|c|}{ 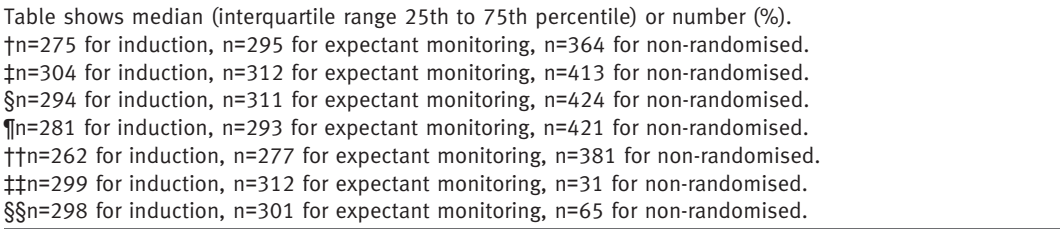 } \\
\hline
\end{tabular}

after spontaneous onset of labour. No cause for her death was found at post mortem and it was classified as a serious unrelated adverse event. No women in the expectant monitoring group died during the study.

Neonatal outcomes are shown in table 4 . There were no stillbirths or perinatal deaths. A total of 17 (5.3\%) neonates in the induction arm and $20(6.1 \%)$ neonates in the expectant monitoring arm had the primary composite adverse neonatal outcome (difference $-0.8 \%$, $95 \%$ CI $-4.3 \%$ to $2.8 \%$ ). No differences between groups in any of the components of the composite adverse neonatal outcome were found. Median birth weight was lower in the induction group than in the expectant monitoring group $(2420$ g $v 2550$ g;
Table 2 | Onset of labour

\begin{tabular}{|c|c|c|c|}
\hline & $\begin{array}{l}\text { Induction of } \\
\text { labour group } \\
\quad(n=321)\end{array}$ & $\begin{array}{c}\text { Expectant } \\
\text { monitoring } \\
\text { group }(n=329)\end{array}$ & $\begin{array}{c}\text { Difference in } \\
\text { mean or } \\
\text { percentage } \\
(95 \% \mathrm{Cl})\end{array}$ \\
\hline $\begin{array}{l}\text { Time between } \\
\text { randomisation } \\
\text { and onset of } \\
\text { labour (days) }\end{array}$ & $0.9(0.7-1.7)$ & $10.4(5.6-16.0)$ & $\begin{array}{c}-9.6(-10.8 \text { to } \\
-8.5)\end{array}$ \\
\hline $\begin{array}{l}\text { Gestational age } \\
\text { at birth (days) }\end{array}$ & $266(261-271)$ & $277(269-283)$ & $\begin{array}{c}-9.9(-11.3 \text { to } \\
-8.6)\end{array}$ \\
\hline \multicolumn{4}{|l|}{ Onset of labour } \\
\hline Spontaneous & $12(3.7)$ & $151(46.0)$ & $\begin{array}{c}-42.3(-48.1 \text { to } \\
-36.5)\end{array}$ \\
\hline $\begin{array}{l}\text { Planned } \\
\text { caesarean } \\
\text { section }\end{array}$ & $2(0.6)$ & $11(3.3)$ & $\begin{array}{c}-2.7(-4.9 \text { to } \\
-0.6)\end{array}$ \\
\hline Induction & $306(95.6)$ & $166(50.6)$ & $\begin{array}{c}45.0(39.2 \text { to } \\
50.9)\end{array}$ \\
\hline
\end{tabular}

Table shows median (interquartile range 25 th to 75 th percentile) or number (\%).

difference $-130 \mathrm{~g}, 95 \% \mathrm{CI}-188$ to $-71 ; \mathrm{P}<0.001)$. Despite this difference, more fetuses in the expectant monitoring arm had a birth weight below the third percentile (100 (31\%) v 40 (13\%); difference $-18.1 \%, 95 \%$ CI $-24.3 \%$ to $-12.0 \% ; \mathrm{P}<0.001)$.

The numbers of infants admitted to neonatal intensive care and median duration of stay in unit was comparable between the two groups $(9(2.8 \%)$ from the induction group and $13(4.0 \%)$ in the expectant monitoring group; duration 9 days, IQR 6-14 and 13 days, IQR 6-22, respectively). However, more neonates in the induction group were admitted to a ward providing an intermediate level of neonatal care $(155(48.4 \%)$ v 118 (36.3\%); difference $12.1 \%, 95 \%$ CI $4.6 \%$ to $19.7 \% ; \mathrm{P}<0.05)$.

Exclusion of pregnancies complicated by hypertensive disease at randomisation did not alter the results for the composite adverse neonatal outcome or caesarean section (data not shown). Stratified analysis for centre and parity using logistic regression showed no treatment differences among the participating centres (data not shown).

\section{DISCUSSION}

This study has shown that among women with a singleton pregnancy complicated by suspected intrauterine growth restriction at a gestational age of between $36+0$ and $41+$ 0 weeks, a policy of labour induction affects neither the rate of adverse neonatal outcomes nor the rates of instrumental vaginal delivery or caesarean section.

The present study has only ruled out a difference in adverse neonatal outcomes larger than $4.3 \%$. We have not ruled out an effect on the rarer outcome of perinatal death. One theoretical argument in favour of induction is that it might pre-empt intrauterine fetal death, so clinicians who wish to follow expectant management should monitor the ongoing pregnancy closely.

In our study the number of admissions to neonatal intensive care was comparable in both arms, but more neonates in the induction group were admitted to intermediate levels of care. This finding might be an artefact 


\section{Table 3|Pregnancy outcomes}

\begin{tabular}{|c|c|c|c|}
\hline & $\begin{array}{l}\text { Induction of labour } \\
\text { group }(n=321)\end{array}$ & $\begin{array}{l}\text { Expectant } \\
\text { monitoring group } \\
(n=329)\end{array}$ & $\begin{array}{l}\text { Difference in mean or } \\
\text { percentage }(95 \% \mathrm{Cl})\end{array}$ \\
\hline \multicolumn{4}{|l|}{ Mode of delivery } \\
\hline Spontaneous vaginal delivery & $249(77.6)$ & $257(78.1)$ & $-0.5(-6.9$ to 5.8$)$ \\
\hline Vaginal instrumental & $27(8.4)$ & $27(8.2)$ & $0.2(-4.0$ to 4.4$)$ \\
\hline Caesarean section & $45(14.0)$ & $45(13.7)$ & $0.3(-5.0$ to 5.6$)$ \\
\hline \multicolumn{4}{|l|}{ Indications for caesarean section } \\
\hline $\begin{array}{l}\text { Suspected fetal distress (with or } \\
\text { without arrest of labour) }\end{array}$ & $37(82.2)$ & $40(88.9)$ & $-6.7(-21.1$ to 7.8$)$ \\
\hline Arrest of labour & $5(11.1)$ & $2(4.4)$ & $6.7(-4.3$ to 17.6$)$ \\
\hline Other & $3(6.7)$ & $3(6.7)$ & $0.0(-10.3$ to 10.3$)$ \\
\hline \multicolumn{4}{|c|}{ Indications for instrumental vaginal delivery } \\
\hline $\begin{array}{l}\text { Suspected fetal distress (+/- arrest } \\
\text { of labour) }\end{array}$ & $21(77.8)$ & $25(92.6)$ & $-14.8(-33.3$ to 3.7$)$ \\
\hline Arrest of labour & $6(22.2)$ & $2(7.4)$ & $14.8(-3.7$ to 33.3$)$ \\
\hline \multicolumn{4}{|l|}{ Adverse maternal outcome } \\
\hline Maternal death & $1(0.3)$ & 0 & NA \\
\hline $\begin{array}{l}\text { Progression to gestational } \\
\text { hypertension }\end{array}$ & $1(0.3)$ & $6(1.8)$ & $-1.5(-3.1$ to 0.1$)$ \\
\hline Progression to pre-eclampsia & $12(3.7)$ & $26(7.9)$ & $-4.2(-7.7 \text { to }-0.6)^{*}$ \\
\hline $\begin{array}{l}\text { Eclampsia, lung oedema, } \\
\text { thromboembolic events }\end{array}$ & 0 & 0 & NA \\
\hline Abruption placentae (partial) & $1(0.3)$ & 0 & NA \\
\hline Postpartum haemorrhage & $10(3.2)$ & $15(4.7)$ & $-1.5(-4.5$ to 1.5$)$ \\
\hline \multicolumn{4}{|l|}{ Maternal admission (days) $\dagger$} \\
\hline Length of stay in hospital & $4(2-6)$ & $4(2-7)$ & ** \\
\hline $\begin{array}{l}\text { Table shows median (IQR 25th to } 75 \\
{ }^{*} \mathrm{P}<0.05 ;{ }^{*} \mathrm{P}=0.2 \text { (Mann-Whitney test } \\
\dagger \mathrm{n}=232 \text { admitted for induction, } \mathrm{n}=24\end{array}$ & $\begin{array}{l}\text { ercentile) or numbe } \\
\text { dmitted for expecta }\end{array}$ & $\begin{array}{l}\%) \text {. } \\
\text { monitoring. } N A=n\end{array}$ & icable. \\
\hline
\end{tabular}

of the inevitable lower birth weight in this group given that the policy was to admit infants below a certain weight, but complications of late prematurity cannot be ruled out. Limiting induction to infants with a gestational age of greater than 37 weeks would reduce the incidence of this outcome, but we cannot know whether this approach would be associated with better long term outcomes. ${ }^{27}$

The higher median birth weight in the expectant monitoring group indicates that infants in this group gained on average $130 \mathrm{~g}$ during the roughly 10 additional days' gestation they experienced compared with the induction group. Presumably, although most neonates in the present trial were born with a weight below the 10th percentile, a number were not really growth restricted but rather constitutionally small. Constitutionally small infants have the potential to grow at term, whereas growth restricted infants might experience intrauterine undernourishment and decelerated growth. We also observed that the number of children with a birth weight below the third percentile differed significantly between the induction of labour group $(12.5 \%)$ and the expectant monitoring group (31\%). This suggests that a substantial number of children in the expectant monitoring group did not continue to grow along their own expected growth curves. Being born severely growth restricted appears to be associated with worse long term outcomes. ${ }^{27}$ Although not defined as a primary outcome in our study, this
Table 4 | Neonatal outcomes

\begin{tabular}{|cccc} 
& $\begin{array}{c}\text { Induction of } \\
\text { labour } \\
\text { group } \\
(n=321)\end{array}$ & $\begin{array}{c}\text { Expectant } \\
\text { monitoring } \\
\text { group } \\
(n=329)\end{array}$ & $\begin{array}{c}\text { Difference in } \\
\text { mean or } \\
\text { percentage } \\
(95 \% \mathrm{Cl})\end{array}$ \\
\hline Birth weight $(\mathrm{g})$ & $2420(2220-$ & $2550(2255-$ & $-130(-188$ to \\
& $2660)$ & $2850)$ & $-71)^{\star *}$
\end{tabular}

Birthweight

percentiles†

\begin{tabular}{|c|c|c|c|}
\hline «Third percentile & $40(12.5)$ & $100(30.6)$ & $\begin{array}{c}-18.1(-24.3 \text { to } \\
-12.0)^{\star \star}\end{array}$ \\
\hline $\begin{array}{l}\text { Third to fifth } \\
\text { percentile }\end{array}$ & $82(25.5)$ & $79(24.2)$ & $1.3(-5.3$ to 8.0$)$ \\
\hline $\begin{array}{l}\text { Fifth to } 10 \text { th } \\
\text { percentile }\end{array}$ & $88(27.4)$ & $62(18.9)$ & $8.5(-2.0$ to 14.9$)$ \\
\hline $\begin{array}{l}\text { 10th to } 25 \text { th } \\
\text { percentile }\end{array}$ & $88(27.4)$ & $66(20.2)$ & $7.2(0.7$ to 13.8$)$ \\
\hline 225th percentile & $23(7.2)$ & $20(6.1)$ & $-1.1(-2.8$ to 4.9$)$ \\
\hline $\begin{array}{l}\text { Composite adverse } \\
\text { neonatal outcome }\end{array}$ & $17(5.3)$ & $20(6.1)$ & $-0.8(-4.3$ to 2.8$)$ \\
\hline Fetal deaths & 0 & 0 & - \\
\hline Neonatal deaths & 0 & 0 & - \\
\hline $\begin{array}{l}\text { Apgar score after five } \\
\text { minutes }<7\end{array}$ & $7(2.2)$ & $2(0.6)$ & $1.6(-0.2$ to 3.4$)$ \\
\hline Arterial $\mathrm{pH}<7.15 \ddagger$ & $34(12.2)$ & $38(13.2)$ & $-1.0(-6.5$ to 4.5$)$ \\
\hline Arterial $\mathrm{pH}<7.10 \ddagger$ & $12(4.3)$ & $19(6.6)$ & $-2.3(-6.0$ to 1.4$)$ \\
\hline Arterial $\mathrm{pH}<7.05 \ddagger$ & $4(1.4)$ & $10(3.5)$ & $-2.1(-4.6$ to 0.5$)$ \\
\hline $\begin{array}{l}\text { Arterial base excess } \\
\text {-10‡ }\end{array}$ & $16(5.7)$ & $26(9.0)$ & $-3.3(-7.6$ to 1.0$)$ \\
\hline $\begin{array}{l}\text { Admission to } \\
\text { intensive care }\end{array}$ & $9(2.8)$ & $13(4.0)$ & $-1.2(-4.0$ to 1.6$)$ \\
\hline \multicolumn{4}{|l|}{ Neonatal admission } \\
\hline Intermediate care & $155(48.4)$ & $118(36.3)$ & $\begin{array}{c}12.1(4.6 \text { to } 19.7) \\
\star\end{array}$ \\
\hline Maternal ward & $89(27.8)$ & $116(35.7)$ & $\begin{array}{c}-7.9(-15.0 \text { to } \\
-0.7)^{\star}\end{array}$ \\
\hline No admission & 67 (20.9) & $78(24.0)$ & $-3.1(-9.5$ to 3.4$)$ \\
\hline \multicolumn{4}{|l|}{ Length of stay (days) } \\
\hline $\begin{array}{l}\text { Infants in the } \\
\text { neonatal intensive care } \\
\text { unit }\end{array}$ & $9(6-14)$ & $13(6-22)$ & $\star \star \star \star$ \\
\hline All admissions & $4(2-8)$ & $4(2-8)$ & $0.2(-1.4$ to 1.8$)$ \\
\hline
\end{tabular}

Table shows median (IQR 25th to 75th percentile) or number (\%)

${ }^{*} \mathrm{P}<0.05$; ${ }^{*} \mathrm{P}<0.001$; ${ }^{* \star *} \mathrm{P}=0.2$ (Mann-Whitney test).

†Percentiles according to Dutch fetal growth charts (weight related to gestational age). ${ }^{36}$

$\ddagger n=279$ for induction, $n=288$ for expectant monitoring.

suggestion could be a compelling reason for induction and certainly merits further investigation.

When women with hypertension or pre-eclampsia at the time of randomisation were excluded, the incidence of the composite adverse neonatal outcome did not differ between the study groups, nor did this result in a lower incidence of caesarean section among women in the expectant monitoring group. Results from the HYPITAT trial support a strategy of inducing women who develop a hypertensive disorder after 37 weeks of pregnancy to prevent possible maternal complications. ${ }^{21}$ This probably also applies to women who develop hypertensive disorders in addition to growth restriction, but the number of such women in this trial was too small to investigate this possibility in detail. 


\section{Comparison with other studies}

Previous observational studies suggest that antenatal detection and induction are associated with an increased incidence of obstetric interventions, without a demonstrable neonatal benefit. ${ }^{12-14}$ However, our finding of no effect of induction on adverse neonatal outcomes, which is from a randomised trial, should supersede findings from observational studies. The finding that induction did not affect the rate of operative deliveries in our study should also not be surprising because observational studies that suggested an increase in operative intervention with induction have been contradicted by later randomised trials. Observational studies of the effect of induction near term for other fetal indications - such as post-maturity, ruptured membranes, and hypertensive disease - on the rate of operative deliveries have been similarly misleading. ${ }^{2829}$

A similar trial of timed delivery among much more severely compromised pre-term fetuses, the Growth Restriction Intervention Trial (GRIT), was reported in $2004 .^{3031}$ At two year follow-up, the risk of disability was reduced in the delayed delivery group compared with the immediate delivery group among babies younger than 31 weeks of gestation at randomisation. Because growth restriction is associated with a less favourable neurodevelopmental outcome in the term period as well as poor outcomes at delivery, ${ }^{32}$ we plan to investigate the wellbeing of the children randomised during DIGITAT at two year follow-up.

\section{Strengths and limitations of study}

The main strength of this study is the comparison of randomised groups and the large size of the study population. There have been no other randomised trials in this area.

Identifying fetuses at risk of true intrauterine growth restriction is a diagnostic challenge. Customised growth centile charts ${ }^{33}$ are rarely applied in the Netherlands and were not used in the present study, but might identify fetuses at risk. Although we encountered no perinatal deaths among the randomised women, the

\section{WHAT IS ALREADY KNOWN ON THIS TOPIC}

Induction of labour is commonly recommended for intrauterine growth restriction near term to prevent possible neonatal morbidity or stillbirth

Induction might also increase neonatal respiratory problems and operative delivery rates; therefore, expectant management with maternal and fetal monitoring remains a commonly followed strategy

\section{WHAT THIS STUDY ADDS}

Fetal and maternal outcomes after induction of labour are equivalent to those with expectant monitoring in women with suspected intrauterine growth restriction at term

Induction is not associated with any increase in operative and instrumental delivery rates

Infants with suspected growth restriction are more likely to be admitted to an intermediate level of care after induction of labour than after expectant monitoring, possibly as a result of complications of late prematurity

It is rational to choose induction in patients with intrauterine growth restriction near term to prevent possible neonatal morbidity and stillbirth, and future studies should focus on the optimal timing of induction association between low birth weight and perinatal death is well accepted. ${ }^{1-4}$ However, many thousands of participants would be required to power a study on the effects of induction on perinatal death.

The relatively favourable neonatal outcomes in both study groups could reflect the fact that participants and clinicians were more alert to possible complications and women received cautious attention from their doctors. Monitoring is also intensified in ordinary practice in the Netherlands, but monitoring and therefore neonatal outcomes could have been biased because of the study setting. The study results should be extrapolated with caution to settings where close monitoring cannot be offered.

It was possible to defer delivery in the expectant monitoring group for on average 9.6 days after randomisation, resulting in an average gestational age of 39+ 3 weeks. Prolongation of gestational age in this group led to more instances of spontaneous vaginal delivery than in the induction group, but did not reduce the number of caesarean sections. Compared with other countries (that is, the United States and the United Kingdom), rates of caesarean section in the Netherlands have always been relatively low, ${ }^{34}$ and the rate in this group of high risk pregnancies was even lower than the average rate of $15 \%$ in the Netherlands. ${ }^{25}$

The fact that women who declined randomisation were older, more highly educated, and smoked less might suggest that the study recruited a slightly biased group of women. This may have an effect on the generalisability of the results.

\section{Conclusions and policy implications}

In conclusion, we found equivalent fetal and maternal outcomes for induction and expectant monitoring in women with suspected intrauterine growth restriction at term, indicating that both approaches are acceptable. In practice, however, obstetricians and patients will let factors other than growth restriction guide decision making at delivery. ${ }^{35}$ It is reasonable for patients who are keen on non-intervention to choose expectant management with intensive maternal and fetal monitoring because, as far as we can tell, this approach is safe for the baby. However, it is more rational to choose induction to prevent possible neonatal morbidity and stillbirth on the grounds that we showed no increase in operative and instrumental delivery rates. However, our study was underpowered to show differences in late pregnancy loss.

By inducing labour in cases of intrauterine growth restriction, infants who will not grow any further can be released from their undernourished environment Future studies should focus on how to distinguish before childbirth fetuses with genuine growth restriction and those that are constitutionally small, and on elucidating which antepartum factors predict adverse outcomes.

We thank the research nurses, midwives, and secretaries of our consortium, and the residents, nurses, and gynaecologists of the participating centres, for their help with participant recruitment and data collection.

Contributors: SAS and JGT conceived and contributed to the design of the trial. SAS and BWJM wrote the grant application and obtained funding for the study. All authors participated in designing the study, recruited participants, and collected data. KEB, SAS and CIS analysed and interpreted the data. KEB drafted the report and SAS, JGT, BWJM, JAMvdP, FJMER, and JMMVL provided 
background knowledge to the data analysis and interpretation. All authors reviewed the report. All authors have seen and approved the final version. The DIGITAT collaborators are: P J A van der Lans (Twenteborg Hospital, Almelo); G Kleiverda (Flevo Hospital, Almere); $\mathrm{M} H \mathrm{~B}$ Heres (Sint Lucas Andreas, Amsterdam); M Wouters (VU Medical Centre, Amsterdam); A J M Huisjes (Gelre Hospital, Apeldoorn); M J Noordam (Lievensberg Hospital, Bergen op Zoom); D N M Papastonis (Amphia Hospital, Breda); RJ P Rijnders (Jeroen Bosch Hospital, Den Bosch); W J van Wijngaarden (Bronovo Hospital, Den Haag); M E van Huizen (Haga Leyenburg, Den Haag); C J de Groot (Medical Centre Haaglanden Den Haag); R H Stigter (Deventer Hospital, Deventer); B M C Akerboom (Albert Schweizer Hospital, Dordrecht); I M Burggraaff (Scheper Hospital, Emmen); A J van Loon (Martini Hospital, Groningen); P J M Pernet (Kennermer Gasthuis, Haarlem); A Lub (Spaarne Hospital, Haarlem); J G Santema (Medical Centre Leeuwarden, Leeuwarden); F J A Copraii (Diaconessenhuis, Leiden); L S M Ribbert (Sint Antonius Hospital, Nieuwegein); J M J Sporken (CanisiusWilhelmina Hospital, Nijmegen); J W de Leeuw (Ikazia Hospital, Rotterdam); PE van der Moer (Maasstad Hospital, Rotterdam); N van Gemund (St Franciscus Gasthuis, Rotterdam); R Aardenburg (Maasland Hospital, Sittard); C M van Oirschot (St Elisabeth Hospital, Tilburg); A P Drogtrop (Twee Steden Hospital, Tilburg); J P R Doornbos (Zaans Medical Centre, Zaandam); AA van Ginkel (Alysis Zorggroep, Zevenaar); and I van Eyck (Isala Hospital, Zwolle). Funding: The study was funded by ZonMw, the Netherlands Organisation for Health Research and Development healthcare efficiency programme (grant number 945-04-558). The funder had no role in study design; collection, analysis, and interpretation of data; writing of the report; or the decision to submit the paper for publication. The corresponding author had full access to all data and final responsibility for the decision to submit for publication.

Conflicts of interest: All authors have completed the Unified Competing Interest form at www.icmje.org/coi_disclosure.pdf (available on request from the corresponding author) and declare: they had support from ZonMw, the Netherlands Organisation for Health Research and Development, for the submitted work; no financial relationships with any organisations that might have an interest in the submitted work in the previous three years; and no other relationships or activities that could appear to have influenced the submitted work.

Ethical approval: This study was approved by the University of Leiden institutional review board (P04.210). Written informed consent was obtained from all participants before randomisation.

Data sharing: Not applicable.

1 Clausson B, Cnattingius S, Axelsson O. Preterm and term births of small for gestation age infants: population-based study of risk factors among nulliparous women. Br J Obstet Gynecol 1998;105:1011-7.

2 McIntire DD, Bloom SL, Casey BM, Leveno KJ. Birth weight in relation to morbidity and mortality among newborn infants. $N$ Engl / Med 1999;340:1234-8.

3 Kramer MS, Olivier M, McLean FH, Willis DM, Usher RH. Impact of intrauterine growth retardation and body proportionality on foetal and neonatal outcome. Pediatrics 1990;86:707-13.

4 Boulet SL, Alexander GR, Salihu HM, Kirby RS, Carlo WA. Fetal growth risk curves: defining levels of fetal growth restriction by neonatal death risk. Am J Obstet Gynecol 2006;195:1571-7.

5 Dijxhoorn MJ, Visser GHA, Touwen BCL, Huisjes HJ. Apgar score, meconium and acidaemia at birth in small-for-gestational age infants born at term, and their relation to neonatal neurological morbidity. Br J Obstet Gynecol 1987;94:873-9.

6 Soothill PW, Ajayi RA, Campbell S, Nicolaides KH. Prediction of morbidity in small and normally grown fetuses by fetal heart rate variability, biophysical profile score and umbilical artery Doppler studies. Br J Obstet Gynecol 1993;100:742-52.

7 Jacobsson B, Ahlin K, Francis A, Hagberg G, Hagberg H, Gardosi J. Cerebral palsy and restricted growth status at birth: populationbased case-control study. Br J Obstet Gynecol 2008;115:1250-5.

8 Low JA, Galbraith RS, Muir D, Killen H, Karchmar J, Campbell D. Intrauterine growth retardation: a preliminary report of long-term morbidity. Am J Obstet Gynecol 1978;130:534-45.

9 Janvis S, Glinianaia SV, Torrioli MG, Platt MJ, Miceli M, Jouk PS, et al: Surveillance of Cerebral Palsy in Europe (SCPE) collaboration of European Cerebral Palsy Registers. Cerebral palsy and intrauterine growth in single births: European collaborative study. Lancet 2003;362:1106-11.

10 Barker DJ. Fetal growth and adult disease. Br J Obstet Gynecol 1992;99:275-82.

11 Pulver LS, Guest-Warnick G, Stoddard GJ, Byington CL, Young PC. Weight for gestational age affects the mortality of late preterm infants. Pediatrics 2009;123:1072-7.
12 Ohel G, Ruach M. Perinatal outcome of idiopathic small for gestational age pregnancies at term: the effect of antenatal diagnosis. Int / Gynaecol Obstet 1996:55:29-32.

13 Jahn A, Razum O, Berle P. Routine screening for intrauterine growth retardation in Germany: low sensitivity and questionable benefit for diagnosed cases. Acta Obstet Gynecol Scand 1998;77:643-8.

14 Hershkowitz R, Erez O, Sheiner E, Bashiri A, Furman B, Shoham-Vardi I, et al. Comparison study between induced and spontaneous term and preterm births of small-for-gestational-age neonates. Eur J Obstet Gynecol Reprod Biol 2001;97:141-6.

15 Engle WA, Kominiarek MA. Late preterm infants, early term infants, and timing of elective deliveries. Clin Perinatol 2008;35:325-41.

16 Chauhan SP, Gupta LM, Hendrix NW, Berghella V: American College of Obstetricians and Gynecologists. Intrauterine growth restriction: comparison of American College of Obstetricians and Gynecologists practice bulletin with other national guidelines. Am J Obstet Gynecol 2009;200:409.

17 Vrouenraets FPJM, Roumen FJME, Dehing CJG, van den Akker ES, Aarts MJ, Scheve El. Bishop score and risk of cesarean delivery after induction of labor in nulliparous women. Obstet Gynecol 2005;105:690-7.

18 Van Gemund N, Hardeman A, Scherjon SA, Kanhai HHH. Intervention rates after elective induction of labor compared to labor with spontaneous onset. A matched cohort study. Gynecol Obstet Invest 2003;56:133-8.

19 Van den Hove MM, Willekes C, Roumen Fl, Scherjon SA. Intrauterine growth restriction at term: induction or spontaneous labour? Disproportionate intrauterine growth intervention trial at term (DIGITAT): a pilot study. Eur J Obstet Gynecol Reprod Biol 2006;125:54-8.

20 Chien PFW, Owen P, Kahn KS. Validity of ultrasound estimation of fetal weight. Obstet Gynecol 2000;95:856-60.

21 Koopmans CM, Bijlenga D, Groen H, Vijgen SM, Aarndouse JG, Bekedam DJ, et al. Induction of labour versus expectant monitoring for gestational hypertension or mild pre-eclampsia after 36 weeks' gestation (HYPITAT): a multicentre, open-label randomised controlled trial. Lancet 2009;374:979-88.

22 Brown MA, Lindheimer MD, de Swiet M, Van Assche A, Moutquin JM. The classification and diagnosis of the hypertensive disorders of pregnancy: statement from the International Society for the Study of Hypertension in Pregnancy (ISSHP). Hypertens Pregnancy 2001;201:IX-XIV.

23 Bishop EH. Pelvic scoring for elective induction. Obstet Gynecol 1964:24:266-8

24 NVOGnet voorlichting \& richtlijnen. Inductie van de baring. 2009. http://nvog-documenten.nl/index.php?pagina=/richtlijn/pagina php\&fSelectTG_62 $=75 \&$ fSelectedSub=62\&fSelectedParent $=75$. [Dutch]

25 The Netherlands Perinatal Registry Foundation. Perinatal care in the Netherlands, 2005. The Netherlands Perinatal Registry Foundation, 2008.

26 Jones B, Jarvis P, Lewis JA, Ebbutt AF. Trials to assess equivalence: the importance of rigorous methods. BMJ 1996;313:36-9.

27 Barker DJ. Adult consequences of fetal growth restriction. Clin Obstet Gynecol 2006;49:270-83.

28 Vrouenraets FP, Roumen F], Dehing CJ, van den Akker ES, Aarts MJ, Scheve EJ. Bishop score and risk of cesarean delivery after induction of labor in nulliparous women. Obstet Gynecol 2005;105:690-7.

29 Kelly Al, Malik S, Smith L, Kavanagh J, Thomas I. Vaginal prostaglandin (PGE2 and PGF2a) for induction of labour at term. Cochrane Database Syst Rev 2009;4:CD003101.

30 GRIT Study Group. A randomised trial of timed delivery for the compromised preterm fetus: short term outcomes and Bayesian interpretation. Br J Obstet Gynaecol 2003;110:27-32.

31 Thornton JG, Hornbuckle J, Vail A, Spiegelhalter DJ, Levene M: GRIT study group. Infant wellbeing at 2 years of age in the Growth Restriction Intervention Trial (GRIT): multicentred randomised controlled trial. Lancet 2004;364:513-9.

32 Roth S, Chang TC, Robson S, Spencer JA, Wyatt JS, Stewart AL. The neurodevelopmental outcome of term infants with different intrauterine growth characteristics. Early Hum Dev 1999;55:39-50.

33 Clausson B, Gardosi I, Francis A, Cnattingius S. Perinatal outcome in SGA births defined by customised versus population-based birthweight standards. Br J Obstet Gynaecol 2001;108:830-4.

34 Betrán AP, Merialdi M, Lauer JA, Bing-Shun W, Thomas J, Van Look P, et al. Rates of caesarean section: analysis of global, regional and national estimates. Paediatr Perinat Epidemiol 2007;21:98-113.

35 Bijlenga D, Birnie E, Mol BW, Bonsel GJ. When outcome is a balance: methods to measure combined utility for the choice between induction of labour and expectant management in mild risk pregnancy at term. BMC Pregnancy Childbirth 2007;7:10.

36 Kloosterman GJ. On intrauterine growth. The significance of prenata care. Int I Gynaecol Obstet 1970;8:895-912.

Accepted: 22 October 2010 